\title{
INTERICTAL SPECT IN THE PRESURGICAL EVALUATION IN EPILEPTIC PATIENTS WITH NORMAL MRI OR BILATERAL MESIAL TEMPORAL SCLEROSIS
}

\author{
Lucia H.N. Marques', José R.L. Ferraz-Filho², Mário L.M. Lins-Filho3, \\ Marina G. Maciel ${ }^{4}$, Rafael Yoshitake ${ }^{4}$, Sarah V. Filetti ${ }^{4}$
}

\begin{abstract}
The aim of this study was to evaluate the sensitivity of interictal compared to ictal SPECT in the lateralization of the epileptogenic focus in refractory temporal lobe epilepsy (TLE) patients that present with normal magnetic resonance imaging (MRI) or bilateral mesial temporal sclerosis (MTS). Thirty patients with TLE, for whom MRI examinations were normal or who presented with bilateral MTS, were retrospectively studied. Using a confidence interval of $95 \%$ and a level of significance for $p$-value $<0.05$, an estimated agreement rate of $73 \%$ with a minimum agreement rate of $57 \%$ was calculated comparing interictal and ictal SPECTs. In conclusion the interictal SPECT is only useful when associated with the ictal SPECT and does not substitute it in the localization of epileptogenic areas in patients with normal MRI or bilateral MTS.
\end{abstract}

KEY WORDS: epilepsy, SPECT, magnetic resonance imaging.

SPECT intercrítico na avaliação pré-cirúrgica de pacientes epiléticos com ressonância magnética normal ou esclerose mesial temporal bilateral

Resumo - O objetivo deste estudo foi avaliar a sensibilidade do SPECT interictal, em relação ao ictal, na lateralização do foco epileptogênico, de pacientes com epilepsia refratária de lobo temporal (ELT) que apresentam ressonância magnética (RM) normal ou esclerose mesial temporal (EMT) bilateral. Foram estudados retrospectivamente 30 pacientes com ELT, nos quais os exames de RM eram normais ou apresentavam EMT bilateral. Avaliada a sensibilidade do SPECT interictal em relação ao ictal, obtivemos taxa estimada de acerto de $73 \%$ com taxa mínima de acerto de $57 \%$, adotando intervalo de confiança de $95 \%$ e índice de significância $\mathrm{p}<0,05$. Conclui-se que o SPECT interictal é necessário apenas quando associado ao SPECT ictal, e não substitui a realização do ictal na localização da AE em pacientes com RM normal ou EMT bilateral.

PALAVRAS-CHAVE: epilepsia, SPECT, ressonância magnética.

Epilepsy is a chronic neurological disorder that affects from $1 \%$ to $3 \%$ of the worldwide population'. It is a syndrome defined by seizures that are the result of a disturbance in the brain's electrical activity. The treatment of epilepsy is, in general, symptomatic ${ }^{2}$. The use of medications provides complete control of seizures in around $80 \%$ of patients ${ }^{3}$ and epilepsy surgery can be indicated for refractory cases ${ }^{4}$. Anterior temporal lobectomy with selective amygdalohippocampectomy, the commonest sur- gical intervention employed, provides good results in $90 \%$ of cases with total remission of the seizures in $66 \%$ of patients and a significant reduction in the frequency of seizures in the other $24 \%{ }^{5,6}$. The success of surgery depends on the identification of the epileptogenic area (EA). Thus, examinations that enable the localization of the EA are necessary. Magnetic resonance imaging (MRI) is the most sensitive examination in the diagnosis of brain structure abnormalities ${ }^{7}$ and is the first-line imaging technique in

\footnotetext{
Neurology Department and Radiology Department (Nuclear Medicine Service) / Medicine School in São José do Rio Preto (FAMERP), São José do Rio Preto SP, Brazil: 'Professor and Doctor of the São José do Rio Preto Epilepsy Surgical Center of Hospital de Base in São José do Rio Preto. Department of Neurology, Medicine School in São José do Rio Preto, FAMERP; ${ }^{2}$ Master in Health Science and Doctor of the Imaging Department of Hospital de Base in São José do Rio Preto; ${ }^{3}$ Assistant Doctor of the Department of Nuclear Medicine, Department of Radiology of the São José do Rio Preto Hospital de Base; ${ }^{4}$ Medicine Student, FAMERP. Financial support: BIC - FAMERP.
}

Received 5 December 2008, received in final form 2 April 2009. Accepted 5 June 2009.

Dra. Lucia Helena Neves Marques - Hospital de Base / Polissonografia - Avenida Brigadeiro Faria Lima 5416 / 69 andar - 15090-000 São José do Rio Preto SP - Brasil. E-mail: neurofisiologia.hbase@famerp.br 
the presurgical evaluation of patients indicated for epilepsy surgery ${ }^{8}$. However there are temporal lobe epilepsy (TLE) patients who present with normal MRI or MRI demonstrating unilateral or bilateral temporal lesions ${ }^{9}$. In these cases other examinations are associated in order to identify the EA, including SPECT (Single Photon Emission Computed Tomography) and Prolonged Electroencephalographic and Video Monitoring (EEG monitoring).

SPECT identifies focal alterations in regional brain blood flow by the endovenous administration of ECD$99^{\mathrm{m}} \mathrm{Tc}$ (ethyl cysteinate dimer marked with technetium$99^{\mathrm{m}}$ ), followed by 3-dimension mapping of the distribution of this agent in the brain ${ }^{10}$ performed in two phases; in the ictal and interictal periods. Refractory epilepsy patients generally present with a scintigraphic pattern of cerebral hypoperfusion ${ }^{11,12}$, normal cerebral perfusion ${ }^{13}$ or, infrequently, hyperperfusion ${ }^{14}$ during the interictal period (outside of seizure) and cerebral hyperperfusion ${ }^{11,15-17}$ of the same area during the ictal period (during the seizures).

Hence, this study aimed at evaluating the sensitivity of interictal SPECT compared with ictal SPECT in refractory TLE patients with normal MRI or bilateral MTS.

\section{METHOD}

Thirty patients ( 22 women and 8 men) with refractory TLE submitted to a presurgical assessment for epilepsy (PSAE) in the Epilepsy Surgical Center of Hospital de Base/FAMERP were included in this retrospective study. The mean age at the time of the surgery was 37.4 years (range: 22 to 58 years old). The MRI examinations of the patients were normal, that is, they did not demonstrate any structural alterations (11 patients) or demonstrated bilateral mesial temporal sclerosis (19 patients). The research Ethics Committee of Hospital de Base/FAMERP approved the study and all patients signed consent forms.

The brain MRI examination was performed using a 1.5T Philips Gyroscan Intera apparatus employing axial, coronal and sagittal plane sequences in FLAIR, T2 TSE, T1 SE and T1 FFE.

EEG monitoring consisted in the simultaneous registration of brain electrical activity with images acquired by video camera. The 64-channel Stellate system that performs this examination enables reformulation of images and prolonged recording of brain electrical activity.

The brain SPECT was performed after a venous injection of 740 to $1480 \mathrm{Mbq}$ (20 to $40 \mathrm{mCi}$ ) of $99 \mathrm{mTc}$-ethyl cysteinate dimer (ECD). In the critical study the injection was applied when patients were being monitored by prolonged EEG and presenting with clinical and electroencephalographic manifestations of epileptic seizures. In the intercritical examinations, the radioisotope was injected at least 24 hours after the last ictal activity documented by EEG monitoring. Images were acquired in a computed head scintillation camera (Elscient SP-4), equipped with a low-energy and highly-sensitive colimeter, using a $360^{\circ}$ acquisition protocol with $6^{\circ}$ intervals and scanning times of 30
Table 1. Localization of interictal SPECT vs. ictal SPECT.

\begin{tabular}{ccc}
\hline SPECT & Consistent & Inconsistent \\
\hline No patients & 22 & 8 \\
$\%$ & 73.33 & 26.67 \\
\hline
\end{tabular}

seconds. The images were reconstructed with the use of filtered back projection followed by attenuation correction $\left(1^{\text {st }}\right.$ order Chang method). Finally transaxial, coronal, temporal and sagital views were obtained, which were qualitatively evaluated, that is, assessed by SPECT color map changes by a specialist in nuclear medicine. The interictal SPECT was initially evaluated in isolation and then in association with the images of the ictal SPECT, with the lateralization of this latter analysis being considered the gold standard and thus employed in the surgical approach of the EA.

Using the normal MRI images or those with signs of bilateral hippocampal sclerosis, the interictal SPECT examinations were analyzed to provide an assessment of the sensitivity of this examination compared to the ictal SPECT. The unilateral test of proportions was applied with a confidence interval of $95 \%$ and a level of significance for $\mathrm{p}$-value $<0.05$.

\section{RESULTS}

Of the 30 patients who had normal MRI or signs of bilateral mesial temporal sclerosis, 29 had lateralization of EA and only one patient had bilateral EA identified by ictal SPECT.

For 22 patients, the interictal SPECT presented hypoperfusion in the temporal region coinciding with the area that demonstrated hyperperfusion in the ictal study (Table 1). Of the remaining eight patients, the interictal SPECT demonstrated: bilateral hypoperfusion and unilateral hyperperfusion in the ictal study in 2 cases; unilateral hyperperfusion associated with ipsilateral hyperperfusion in the ictal SPECT in 1 case and contralateral hyperperfusion in the ictal SPECT in another case. In 3 cases, the hypoperfusion in the interictal study was associated with contralateral hyperperfusion in the ictal SPECT. Only one case showed bilateral hyperperfusion in the ictal SPECT and unilateral hypoperfusion in the interictal SPECT (Table 2).

The statistical evaluation of the sensitivity of the interictal SPECT when compared to the ictal SPECT showed an estimated agreement rate of $73 \%$, varying between $54 \%$ and $88 \%$ ( $p$-value=0.016) and a minimum agreement rate of $57 \%$ (p-value=0.008).

\section{DISCUSSION}

SPECT, in particular during the ictal phase, is considered an important method in the detection of the EA ${ }^{17}$. A systematic review of the efficacy of neuroimaging techniques to locate the EA published in 2006 reported that the ictal SPECT was the most efficacious to locate the EA 
Table 2. Identification, MRI, EEG monitoring, ictal SPECT, interictal SPECT.

\begin{tabular}{|c|c|c|c|c|c|c|}
\hline Case & Gender & Age at surgery & MRI & EEG monitoring & Ictal SPECT & Interictal SPECT \\
\hline 1 & $\mathrm{~F}$ & 40 & $R / L$ & $\mathrm{R}$ & $\mathrm{R}$ & $\mathrm{R}$ \\
\hline 2 & $\mathrm{~F}$ & 45 & $R / L$ & $\mathrm{R}$ & $\mathrm{R}$ & $R / L$ \\
\hline 3 & $\mathrm{~F}$ & 36 & $R / L$ & L & L & Hyper L \\
\hline 4 & $F$ & 39 & $R / L$ & L & L & L \\
\hline 5 & $\mathrm{~F}$ & 37 & $R / L$ & $\mathrm{R}$ & L & L \\
\hline 6 & M & 54 & $R / L$ & $\mathrm{R}$ & $\mathrm{R}$ & $\mathrm{R}$ \\
\hline 7 & $\mathrm{~F}$ & 28 & $R / L$ & L & L & L \\
\hline 8 & $\mathrm{~F}$ & 53 & $R / L$ & L & L & L \\
\hline 9 & $\mathrm{~F}$ & 36 & $R / L$ & $\mathrm{R}$ & $\mathrm{R}$ & $\mathrm{R}$ \\
\hline 10 & $F$ & 31 & $R / L$ & $\mathrm{R}$ & $\mathrm{R}$ & L \\
\hline 11 & $M$ & 27 & $R / L$ & $\mathrm{R}$ & $\mathrm{R}$ & $\mathrm{R}$ \\
\hline 12 & $\mathrm{~F}$ & 22 & $R / L$ & L & L & L \\
\hline 13 & $\mathrm{~F}$ & 33 & $R / L$ & $R$ & $R$ & $R$ \\
\hline 14 & $\mathrm{~F}$ & 34 & $R / L$ & $\mathrm{R}$ & $\mathrm{R}$ & $\mathrm{R}$ \\
\hline 15 & $M$ & 53 & $R / L$ & $\mathrm{R}$ & $\mathrm{R}$ & Hyper L \\
\hline 16 & $\mathrm{~F}$ & 58 & $R / L$ & $\mathrm{R}$ & $\mathrm{R}$ & $R / L$ \\
\hline 17 & $\mathrm{~F}$ & 31 & $R / L$ & $\mathrm{R}$ & $\mathrm{R}$ & $\mathrm{R}$ \\
\hline 18 & $\mathrm{~F}$ & 57 & $R / L$ & $\mathrm{R}$ & $\mathrm{R}$ & L \\
\hline 19 & $\mathrm{~F}$ & 45 & $R / L$ & $\mathrm{R}$ & $\mathrm{R}$ & $\mathrm{R}$ \\
\hline 20 & $M$ & 28 & No & $\mathrm{R}$ & $\mathrm{R}$ & L \\
\hline 21 & $\mathrm{~F}$ & 42 & No & $\mathrm{L}$ & L & L \\
\hline 22 & $F$ & 42 & No & $\mathrm{L}$ & L & L \\
\hline 23 & $M$ & 23 & No & $R$ & $\mathrm{R}$ & $R$ \\
\hline 24 & $\mathrm{~F}$ & 43 & No & $\mathrm{R}$ & $\mathrm{R}$ & $\mathrm{R}$ \\
\hline 25 & $\mathrm{~F}$ & 31 & No & $R$ & $R / L$ & $\mathrm{~L}$ \\
\hline 26 & $M$ & 30 & No & $\mathrm{R}$ & $\mathrm{R}$ & $\mathrm{R}$ \\
\hline 27 & M & 20 & No & $\mathrm{R}$ & $\mathrm{R}$ & $\mathrm{R}$ \\
\hline 28 & $M$ & 24 & No & $\mathrm{R}$ & $\mathrm{R}$ & $\mathrm{R}$ \\
\hline 29 & $\mathrm{~F}$ & 39 & No & L & L & L \\
\hline 30 & $\mathrm{~F}$ & 43 & No & $\mathrm{L}$ & $\mathrm{L}$ & $\mathrm{L}$ \\
\hline
\end{tabular}

F: female; M: male; MRI: magnetic resonance imaging; EEG monitoring: prolonged video electroencephalographic monitoring; R: right; L: left; Hyper: hyperperfusion; No: normal.

in patients with $\mathrm{TLE}^{17}$. In a meta-analysis of the sensitivity of SPECTs and their diagnostic value in the detection of EAs in patients with TLE, a greater sensitivity was observed for the ictal SPECT (97\%), followed by the post-ictal $(75 \%)$ and interictal (44\%) SPECTs ${ }^{18}$.

Despite of the great variation reported in the literature about the sensitivity of the interictal SPECT in identifying lateralization of the EA $(35-80 \%$ - with a mean value of $50 \%)^{19}$, this examination is frequently used in epilepsy treatment centers as it is a simple technique that is readily available with less necessity of specialized staff when compared to the ictal study ${ }^{20}$.
An association between hypoperfusion in the interictal SPECT and hyperperfusion in the ictal SPECT was the commonest finding during the PSAE ${ }^{16}$. However we found variations such as hyperperfusion in the interictal SPECT, even when no seizures were identified within the previous 24 hours or of Periodic Lateralized Epileptiform Discharges (PLED), which may be responsible for this change in the scintigraphic pattern as has been reported in publications in approximately $5 \%$ of interictal studies ${ }^{14}$. The finding of interictal study images with bilateral hypoperfusion and hypoperfusion contralateral to ictal hyperperfusion demonstrate the necessity of other diagnostic approaches in 
dubious cases. Hence, the best option in these cases is the use of ictal EEG for the preoperative location of EAs ${ }^{21}$.

In respect to the ictal SPECT, bilateral hyperperfusion was found in only one patient and interestingly this patient's interictal SPECT demonstrated hypoperfusion contralateral to the EEG monitoring findings and normal MRI. This fact may be explained by the hypothesis that the interictal SPECT can evidence dysfunctional areas related to the EA, which do not always represent the primary focus ${ }^{22}$.

The ictal SPECT is the best technique of functional imaging when the MRI does not define the $\mathrm{EA}^{19}$. Thus, we should consider that the high rate of correct lateralization of this technique contributes to the interictal SPECT evaluation as, the result of the ictal SPECT is obtained after a combined analysis with interictal SPECT images ${ }^{23}$.

In spite of the advantages inherent in interictal SPECT evaluations and the good results in sensitivity, as seen in this study, we can not consider this approach in isolation as there is discordance when compared with the ictal examination and due to its considerably lower sensitivity in TLE patients.

Hence, the interictal SPECT is more specific to locate EAs in patients that present with a normal MRI or bilateral MTS only when evaluated in association with the ictal SPECT and so in these cases it can not substitute the ictal SPECT.

ACKNOWLEDGEMENT - Prof. Dr. José Antonio Cordeiro, PhD in applied mathematics and professor of the Medical School in São José do Rio Preto, for his contribution with the statistical analysis.

\section{REFERENCES}

1. Shneker BF, Fountain NB. Epilepsy review. Dis Mon 2003;49:426-478.

2. Guerreiro CAM, Guerreiro MM, Cendes F, Cendes IL. Considerações gerais. In: Guerreiro CAM, Guerreiro MM, Cendes F, Cendes IL (Eds). Epilepsia. Lemos Editorial, 2000;3:1-10.

3. Annegers JF, Hauser WA, Elveback LR. Remission of seizure and relapse in patients with epilepsy. Epilepsia 1979;20:729-737.

4. Pedley TA, Bazil CW, Morrell MJ. Epilepsia. In: Rowland LP (Eds). Merritt tratado de neurologia. Rio de Janeiro. Guanabara-Koogan; 2002;10: 705-723.

5. Engel J, Van Ness Rasmussen T, Ojeman L. Outcome with respect to epileptic seizures. In: Engel J (Ed). Surgical treatment of the epilepsies. $2^{\text {nd }}$ Ed. New York: Raven Press, 1993:609-621.

6. Elices E, Rumiá J, Cañizares S, et al. Cirurgia de la epilepsia en un centro de referencia. Rev Neurol 2002;37:635-639.

7. Adrian M. Siegel. Presurgical evaluation and surgical treatment of medically refractory epilepsy. Neurosurg Rev 2004;27:1-18.

8. Sperling MR, Wilson G, Engel J Jr, Babb TL, Phelps M, Bradley W. Magnetic resonance imaging in intractable partial epilepsy: correlative studies. Ann Neurol 1986;20:57-62.

9. Alsaadi TM, Bateman LM, Laxer KD, Barbaro NM, Austin EJ, Garcia PA. Potentially misleading extratemporal lobe lesions in patients with temporal lobe epilepsy. J Neurol Neurosurg Psychiatry 2003;74:566-569.

10. Oliveira AJ, Hilário LN, Anselmi OE. SPECT cerebral: princípios e aspectos técnicos. In: Costa JC, Palmini A, Yacubian EMT, Cavalheiro EA (Eds). Fundamentos neurobiológicos das epilepsias: aspectos clínicos e cirúrgicos. Volume I. São Paulo: Lemos, 1998:659-671.

11. Berkovic SF, Newton MR, Chiron C, Dulac O. Single photon emission tomography. In: Engel Jr J (Ed). Surgical treatment of epilepsies. ${ }^{\text {nd }} \mathrm{Ed}$. New York: Raven Press, 1193:233-243.

12. Rowe CC, Berkovic SF, Sia STB, et al. Localization of epileptic foci with postictal single photon emission computed tomography. Ann Neurol 1989;26:660-668.

13. Etchebehere ECSC, Yacubian EMT, Camargo EE. Spect cerebral em epilepsia. In: In: Guerreiro CAM, Guerreiro MM, Cendes F, Cendes IL (Eds). Lemos Editorial, 2000:155-166.

14. Shen W, Lee BI, Park HM, et al. HIPDM-SPECT brain imaging in the presurgical evaluation of patients with intractable seizures. J Nucl Med 1990:31:1280-1284.

15. Duncan JS. Imaging and epilepsy. Brain 1997;120:339-377.

16. Whiting P, Gupta R, Burch J, et al. A systematic review of the effectiveness and cost-effectiveness of neuroimaging assessments used to visualise the seizure focus in people with refractory epilepsy being considered for surgery. Health Technol Assess 2006;10:31-47.

17. Devous MD, Thisted RA, Morgan GF, Leroy RF, Rowe CC. SPECT brain imaging in epilepsy: a meta-analysis. J Nucl Med 1998;39:285-293.

18. Bonte FJ, Devous MD Sr, Stokely EM, et al. Single-photon computed tomographic determination of regional brain blood flow in the seizure disorders. Am J Physiol Imaging 1988;3:30-31.

19. Asenbaum $S$, Baumgartner C. Nuclear medicine in the preoperative evaluation of epilepsy. Nucl Med Commun 2001;22:835-840.

20. Maehara T. Neuroimaging of epilepsy. Neuropathology 2007; 27:585-593.

21. Tatum WO, Benbadis SR, Hussain A, et al. Ictal EEG remains the proeminent predictor of seizure-free outcome after temporal lobectomy in epileptic patients with normal brain MRI. Seizure 2008;17:631-636.

22. Andraus MEC, Cosenza CAN, Fonseca LMB, D’Andrea I, Leon SVA. SPECT cerebral interictal em pacientes com epilepsia de lobo temporal de difícil controle. Arq Neuropsiquiatr 2002;60:779-787.

23. Uijl SG, Leijten FS, Arends JB, Parra J, van Huffelen AC, Moons KG. Decision-making in temporal lobe epilepsy: the contribution of basic non-invasive tests. Seizure 2008;17:364-373. 